\title{
Multi-wavelength optical measurement to enhance thermal/optical analysis for carbonaceous aerosol
}

L.-W. A. Chen et al.

Correspondence to: L.-W. A. Chen (antony.chen@unlv.edu) 
Table S1. List of abbreviations and acronyms used in the paper.

\begin{tabular}{|c|c|}
\hline Abbreviations/Acronyms & Descriptions \\
\hline A & Filter sampling area \\
\hline $\mathrm{ATN}, \mathrm{ATN}_{\lambda}$ & Transmittance attenuation (general, at wavelength $\lambda$ ) \\
\hline $\mathrm{BC}, \mathrm{BC}_{\mathrm{d}}$ & Black carbon (general, diesel elemental carbon equivalent) \\
\hline $\mathrm{BrC}$ & Brown carbon \\
\hline CV-RMSR & Coefficient of variance of root mean square residual \\
\hline $\begin{array}{l}\mathrm{EC}, \mathrm{ECR}, \mathrm{ECR}_{\lambda}, \mathrm{ECT}, \\
\mathrm{ECT}_{\lambda},[\mathrm{EC}]\end{array}$ & $\begin{array}{l}\text { Elemental carbon (general, reflectance adjusted, reflectance } \\
\text { adjusted at wavelength } \lambda \text {, transmittance adjusted, transmittance } \\
\text { adjusted at wavelength } \lambda \text {, areal concentration on filter) }\end{array}$ \\
\hline $\mathrm{He}$ & Helium \\
\hline IMPROVE & Interagency Monitoring of Protected Visual Environments \\
\hline MAE, $\mathrm{MAE}_{\lambda}, \mathrm{MAE}_{\lambda, \mathrm{EC}}$ & $\begin{array}{l}\text { Mass absorption efficiency (general, at wavelength } \lambda \text {, of } \\
\text { elemental carbon at wavelength } \lambda \text { ) }\end{array}$ \\
\hline $\mathrm{M}_{\lambda}$ & Multiple scattering effect coefficient at wavelength $\lambda$ \\
\hline $\mathrm{Ne}$ & Neon \\
\hline $\begin{array}{l}\text { OC, OCR, OCT, OCR } \\
\mathrm{OCT}_{\lambda}\end{array}$ & $\begin{array}{l}\text { Organic carbon (general, reflectance adjusted, reflectance } \\
\text { adjusted at wavelength } \lambda \text {, transmittance adjusted, transmittance } \\
\text { adjusted at wavelength } \lambda \text { ) }\end{array}$ \\
\hline $\mathrm{PM}, \mathrm{PM}_{2.5}$ & Particulate matter (general, less $2.5 \mu \mathrm{m}$ aerodynamic diameter) \\
\hline POC & Pyrolyzed organic carbon \\
\hline $\mathrm{R}, \mathrm{LR}, \mathrm{LR}_{\lambda}, \mathrm{FR}, \mathrm{FR}_{\lambda}$ & $\begin{array}{l}\text { Reflectance (general, laser relative, laser relative at wavelength } \lambda \text {, } \\
\text { filter absolute, filter absolute at wavelength } \lambda \text { ) }\end{array}$ \\
\hline RD & Relative difference \\
\hline $\begin{array}{l}\mathrm{T}, \mathrm{LT}, \mathrm{LT}_{\lambda}, \mathrm{FT}, \mathrm{FT}_{\lambda} \\
\mathrm{FT}_{\lambda, \mathrm{i}}, \mathrm{FT}_{\lambda, \mathrm{f}}\end{array}$ & $\begin{array}{l}\text { Transmittance (general, laser relative, laser relative at wavelength } \\
\lambda \text {, filter absolute, filter absolute at wavelength } \lambda \text {, filter absolute at } \\
\text { wavelength } \lambda \text { before thermal analysis, filter absolute at } \\
\text { wavelength } \lambda \text { after thermal analysis) }\end{array}$ \\
\hline TC & Total carbon \\
\hline TOA & Thermal/optical analysis \\
\hline TSA & Thermal/spectral analysis \\
\hline $\mathrm{V}$ & Filter sampling volume \\
\hline$\alpha, \alpha(\lambda), \alpha_{\mathrm{BC}}, \alpha_{\mathrm{BrC}}$ & $\begin{array}{l}\text { Absorption Angström exponent (general, at wavelength } \lambda \text {, of } \\
\text { black carbon, of brown carbon) }\end{array}$ \\
\hline $\mathrm{b}$ & Regression intercept \\
\hline$b_{a b s}$ & Absorption coefficient \\
\hline $\mathrm{m}$ & Regression slope \\
\hline $\mathrm{p}$ & T-test $\mathrm{p}$ value \\
\hline$\beta_{\lambda}$ & Shadowing effect coefficient at wavelength $\lambda$ \\
\hline$\lambda$ & Wavelength \\
\hline$\tau_{\mathrm{a}}, \tau_{\mathrm{a}, \lambda}, \tau_{\mathrm{a}, \lambda, \mathrm{BC}}, \tau_{\mathrm{a}, \lambda, \mathrm{BrC}}$ & $\begin{array}{l}\text { Absorption optical depth (general, at wavelength } \lambda \text {, at wavelength } \\
\lambda \text { due to black carbon, at wavelength } \lambda \text { due to brown carbon) }\end{array}$ \\
\hline
\end{tabular}




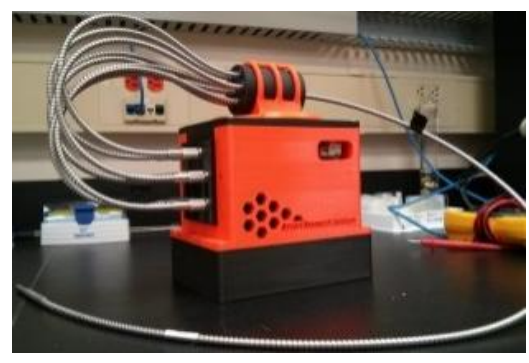

(a)

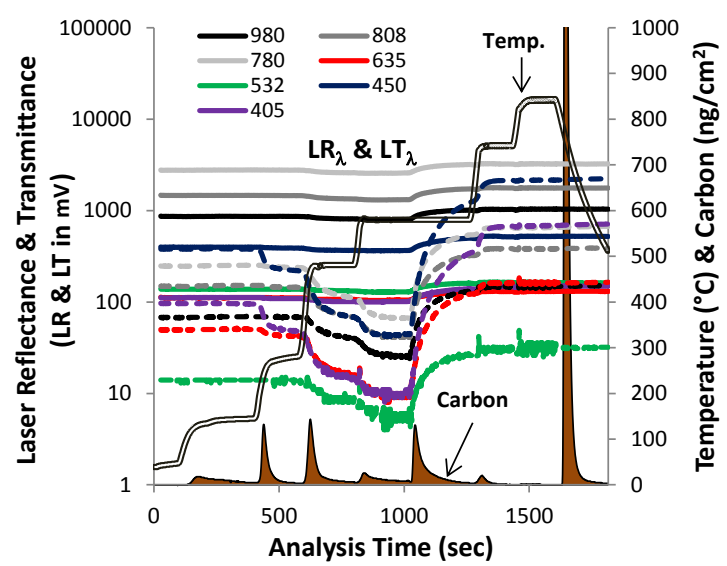

(c)

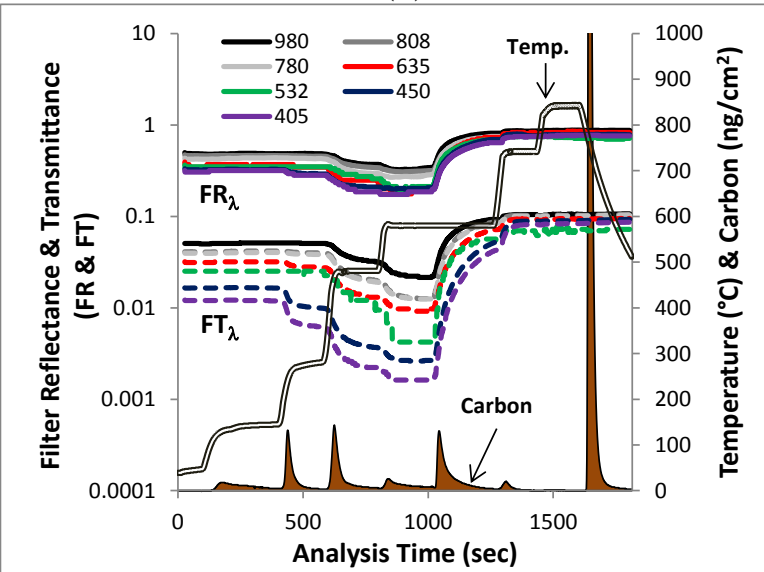

(e)

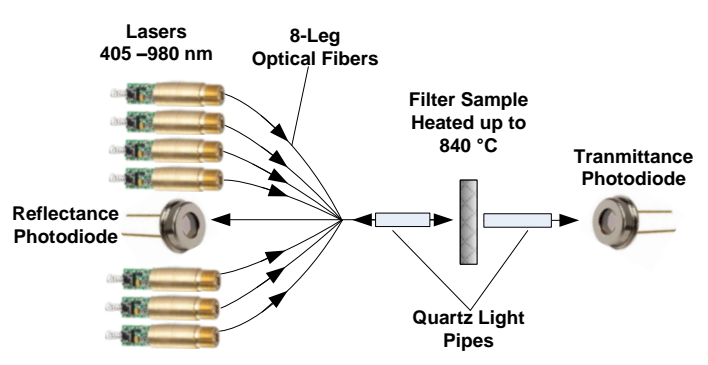

(b)

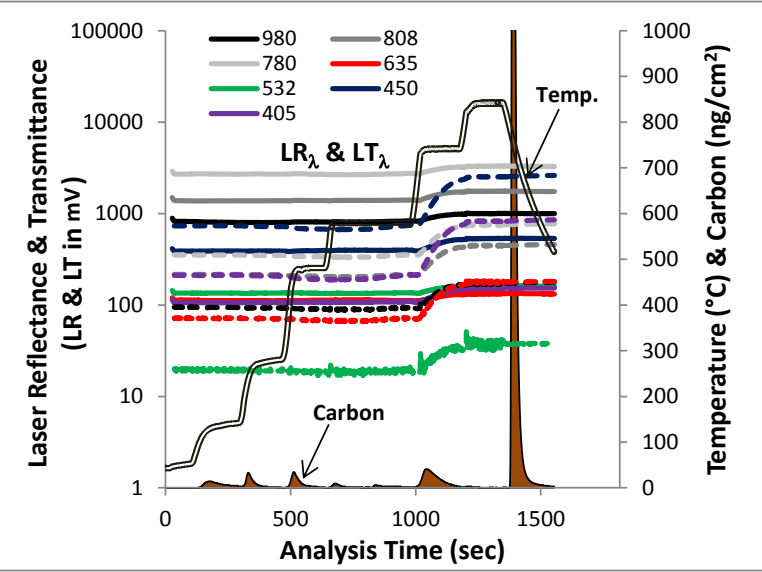

(d)

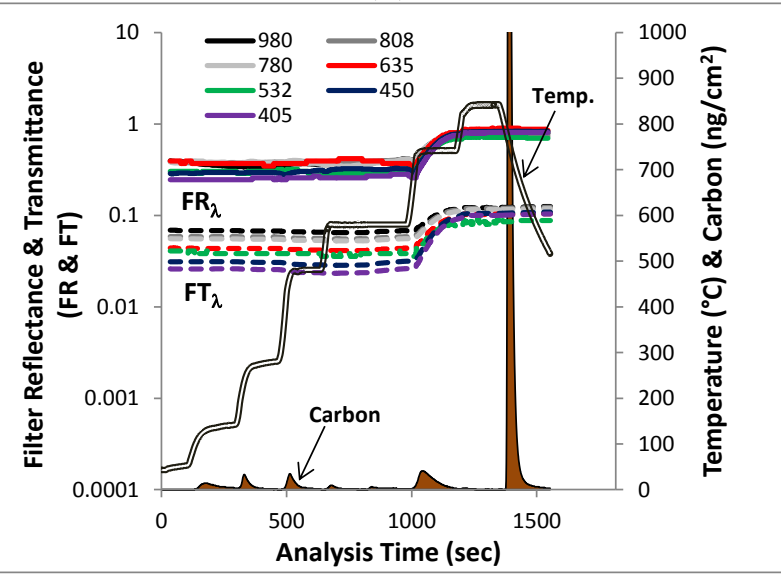

(f)

Figure S1. Configuration of (a) the multi-wavelength module and (b) interface to a thermal/optical carbon Analyzer. Example of typical thermal/spectral analysis (TSA) thermogram for: (c) Fresno ambient and (d) diesel exhaust samples. Laser reflectance $\left(\mathrm{LR}_{\lambda}\right.$, solid lines) and transmittance (LT $\mathrm{LT}_{\lambda}$, dashed lines) at 7 wavelengths $(405,450,532,635,780,808$, and $980 \mathrm{~nm})$ are reported in millivolts $(\mathrm{mV})$ as detected by the photodiodes. Absolute filter reflectance and transmittance $\left(\mathrm{FR}_{\lambda} / \mathrm{FT}_{\lambda}\right)$ for (c) and (d) are shown in (e) and (f), respectively, after calibrating $\mathrm{LR}_{\lambda}$ and $\mathrm{LT}_{\lambda}$ against reflectance and transmittance measurements by the Lambda 35 integrating-sphere spectrometer. $\mathrm{FR}_{\lambda}$ is between 0.1 and 1 (i.e., $100 \%$ ) while $\mathrm{FT}_{\lambda}$ is generally $<0.1(10 \%)$. The temperature steps follow the IMPROVE_A protocol: OC1 $\left(140^{\circ} \mathrm{C}\right), \mathrm{OC} 2$ $\left(280^{\circ} \mathrm{C}\right), \mathrm{OC} 3\left(480^{\circ} \mathrm{C}\right), \mathrm{OC} 4\left(580^{\circ} \mathrm{C}\right), \mathrm{EC} 1\left(580^{\circ} \mathrm{C}\right), \mathrm{EC} 2\left(740^{\circ} \mathrm{C}\right)$, and $\mathrm{EC} 3\left(840^{\circ} \mathrm{C}\right)$ with oxygen introduced at the beginning of EC1. The last carbon peak corresponds to the internal methane standard. 


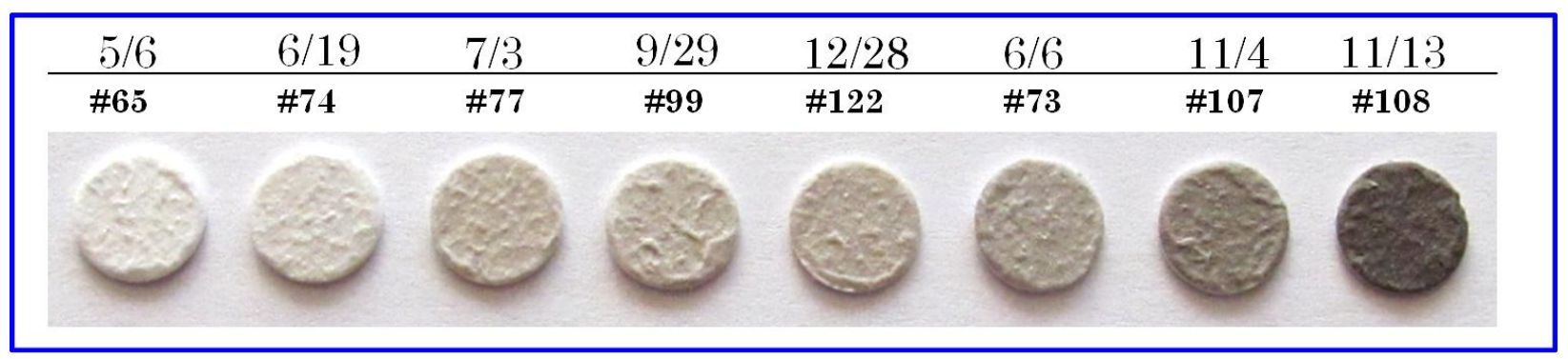

(a)

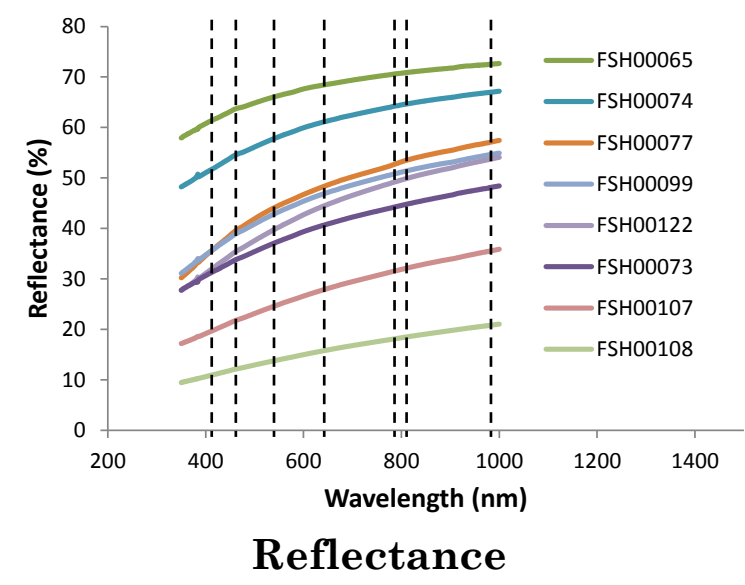

(b)

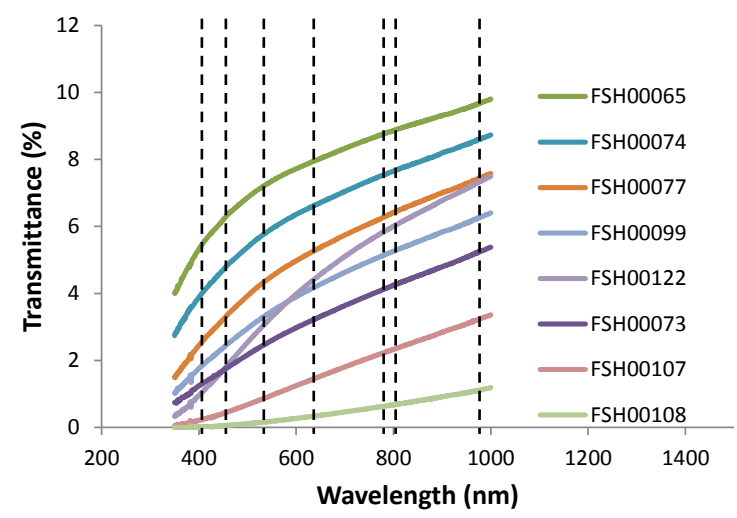

Transmittance

(c)

Figure S2. (a) Fresno Supersite $\mathrm{PM}_{2.5}$ samples acquired from year 2003 serving as transfer standards for calibrating the reflectance and transmittance measurement of a multi-wavelength carbon analyzer. Also shown are the spectral (b) reflectance and (c) transmittance of these samples as quantified by an integrating-sphere spectrometer (Lambda 35, Perkin Elmer, Massachusetts, USA). Dashed lines correspond to wavelengths of the thermal/spectral analysis by the multi-wavelength carbon analyzer. 


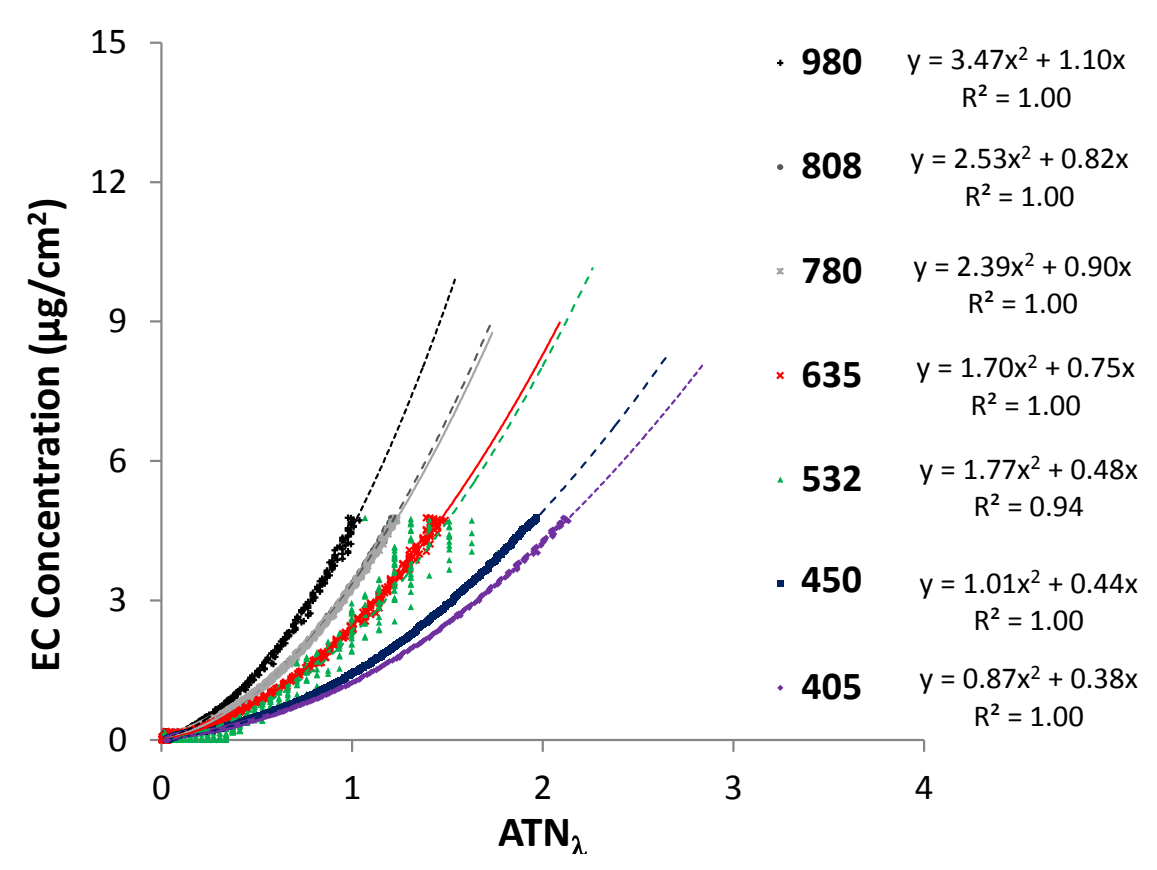

Figure S3. Calibration of $\mathrm{ATN}_{\lambda}$ of the 7-wavelength carbon analyzer with EC loading ([EC]) measured during the EC2 step of IMPROVE_A analysis of a diesel exhaust sample (CIFQ074, acquired from the Gasoline/Diesel Split Study). Regressions are based on Eq. (6).

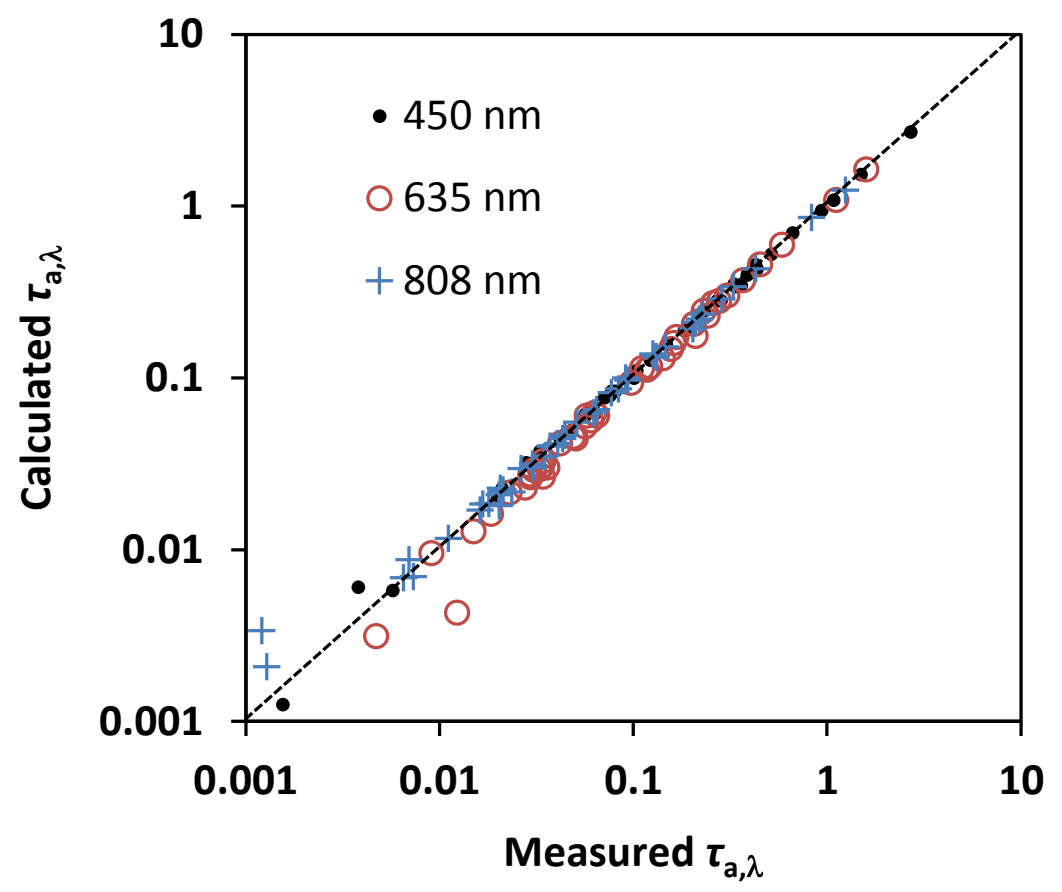

Figure S4. Measured $\tau_{\mathrm{a}, \lambda}\left(450,635\right.$, and $808 \mathrm{~nm}$ are shown) compared with $\tau_{\mathrm{a}, \lambda}$ fitted from Eq. (7) assuming a two-component model. All samples in this study are included. 


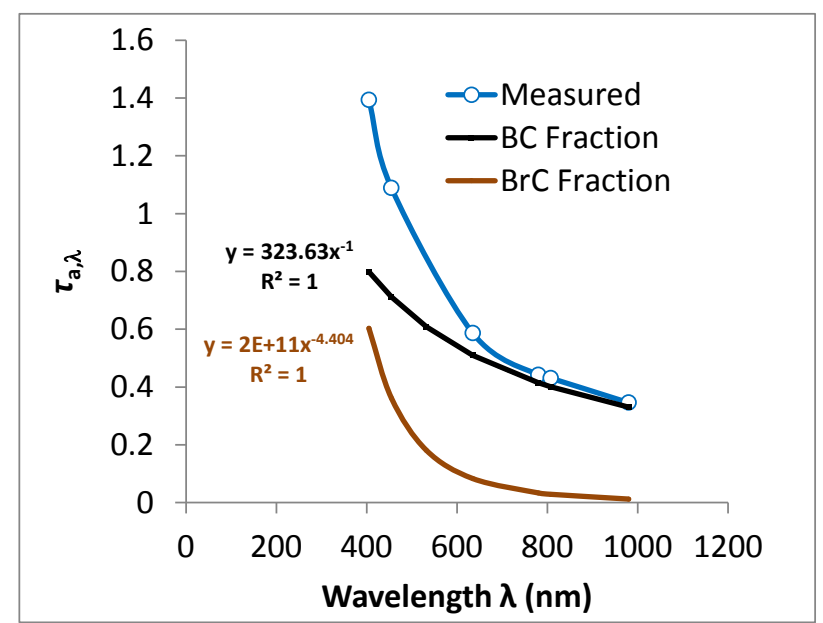

(a)

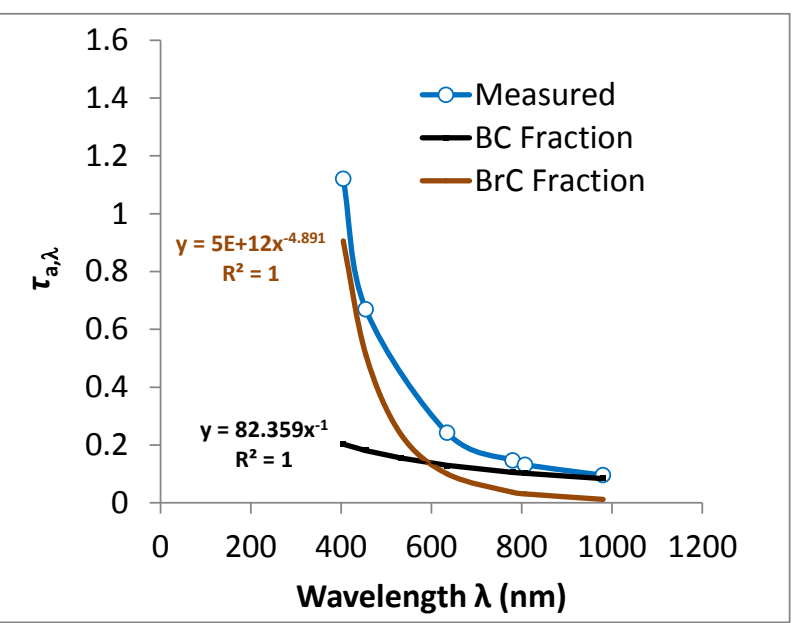

(b)

Figure S5. Decomposition of measured absorption optical depth $\left(\tau_{\mathrm{a}, \lambda}\right)$ from (a) Fresno ambient and (b) Reno wildfire samples into the $\mathrm{BC}$ and $\mathrm{BrC}$ contributions based on their distinct spectral dependence of light absorption. See text for details. 